\title{
Changes in the Sexual Dimorphism of Triatominae in the Transition from Natural to Artificial Habitats
}

\author{
JP Dujardin/+, M Steindel*, T Chavez**, M Machane**, CJ Schofield****
}

\begin{abstract}
UMR CNRS-ORSTOM 9926, ORSTOM BP 5045, 911 Av. Agropolis, Montpellier cedex 1, France *Departamento de Microbiologia e Parasitologia, Universidade Federal de Santa Catarina, Florianopolis, SC, Brasil **Instituto Boliviano de Biologia de Altura, Calle Claudio Sanjinez, La Paz, Bolivia ***Department of Infectious and Tropical Diseases, London School of Hygiene and Tropical Medicine, London WC1 E7HT, UK

A shift from large to small average sizes was observed in Triatoma infestans and Rhodnius domesticus between field and domestic (or laboratory) conditions of life. It was more pronounced in the female specimens, leading to a subsequent reduction of sexual size dimorphism. This feature is discussed in terms of genetic and populational changes occurring from natural to artificial habitats, in particular those related to population densities. Sexual size dimorphism is then recommended as a new character to be used in the study of species of Triatominae adapting to domestic ecotopes.
\end{abstract}

Key words: Triatominae - sexual size dimorphism - silvatic - domestic - laboratory

Triatominae (Hemiptera, Reduviidae) are blood sucking insects widely distributed in Latin America, where several are important vectors of Trypanosoma cruzi, causative agent of Chagas disease (American trypanosomiasis). Most species occur in silvatic ecotopes, associated with small nest-building mammals or birds, but several have made the transition to domestic habitats where they feed on humans and domestic animals, transmitting $T$. cruzi.

Many species can be reared in the laboratory by feeding on laboratory animals such as mice, rabbits or chickens, and various authors have reported a general reduction in average size of specimens reared over several generations (Szumlewicz 1976, Zeledón 1981).

We have also noted a reduction in the sexual dimorphism of head measurements associated with captive breeding of Triatominae, and report here a study of this phenomenon in Rhodnius domesticus (Neiva \& Pinto).

In spite of its name, $R$. domesticus seems to be entirely silvatic, confined to Atlantic forest ecotopes along the Brazilian coast. Although frequently infected with $T$. cruzi, and also T. rangeli, it has little epidemiological significance (Leal et

\footnotetext{
This work was partially supported through the ECLAT network, with grants from the European Commission and Avina Foundation.

${ }^{+}$Corresponding author. ORSTOM La Paz, CP9214, La Paz, Bolivia. Fax: +591-2-243782. E-mail: jpdujard@ceibo.entelnet.bo.

Received 17 September 1998

Accepted 24 February 1999
}

al. 1961, Galvão et al. 1962, Schlemper Jr et al. 1985, Steindel et al. 1991). Colonies of $R$. domesticus originating from the Island of Santa Catarina have been reared at the Federal University of Santa Catarina since 1984, and the species was recently collected again from its natural bromeliad habitats on the Island. Our morphometric comparisons of the laboratory and silvatic samples were prompted by the idea that any metric changes might parallel similar differences that we have seen in silvatic and domestic populations of Triatoma infestans (Klug) in Bolivia (Dujardin \& Casini 1996, Dujardin et al. 1997a,b).

We add to the $R$. domesticus study a similar study in T. infestans, comparing sexual size dimorphism between its silvatic and domestic ecotopes of Bolivia, and we report related observations from published data on R. prolixus (Harry 1992).

\section{MATERIALS AND METHODS}

We examined 22 adult $R$. domesticus, 14 direct from the field collections and 8 from the laboratory colony of the same geographic origin. For comparison we also reexamined published data on the related R. prolixus Stal (Harry 1992, 1994), and T. infestans (Dujardin et al. 1997b). For each of the $R$. domesticus specimens we made 12 head measurements as indicated in Fig. 1. Means and standard deviations for each character (Table I) were compared by sex and biotope using the nonparametric test of Kruskal and Wallis (1952) and each comparison was tested for significance using the sequential Bonferroni test as described by Sokal and Rohlf (1995).

We made a similar comparison for silvatic and domestic T. infestans from Bolivia using the five 

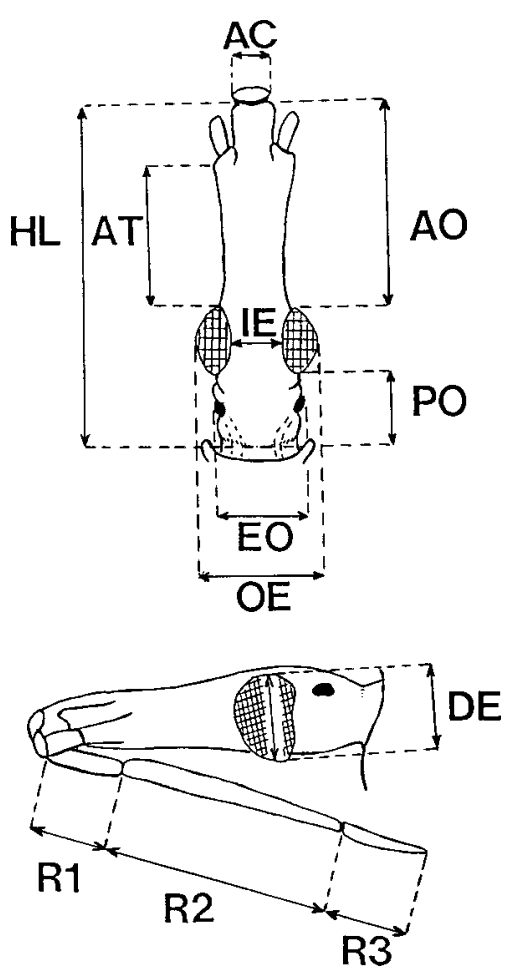

Fig. 1- OE: outer distance between eyes; IE: inner distance between eyes; EO: external distance between ocelli; AO: anteocular distance; PO: postocular distance (excluding neck); HL: head length; DE: diameter of the eye; AT: antenniferous tubercle; R1, R2 and R3: lengths of first, second and third rostral segments, respectively, and AC: width of the anteclypeus.

head measurements retained by Dujardin et al. (1997b) as giving the best accuracy and precision of measurement: OE, PO, HL, AT and R2 (Fig. 1).

We could also carry out multivariate analysis using a covariance-matrix based principal component analysis on log-transformed data from $R$. domesticus and T. infestans. To avoid matrix singularities, two measures of $R$. domesticus (IE and HL, Fig. 1) were discarded because of their partial overlap with other measures. The remaining variables were all significantly correlated with the first principal component (PC1) which contributed $64 \%$ to the overall variation. PC1 could therefore be accepted as a general indicator of size (Bookstein 1989, Dos Reis et al. 1990) so that the resulting factor maps (Fig. 2) clearly illustrate global size differences in the populations analyzed.

\section{RESULTS}

Females from the field collected sample of $R$. domesticus were significantly different from males at almost all measurements, whereas no such difference between males and females was found in the laboratory specimens (Table II, left). This was
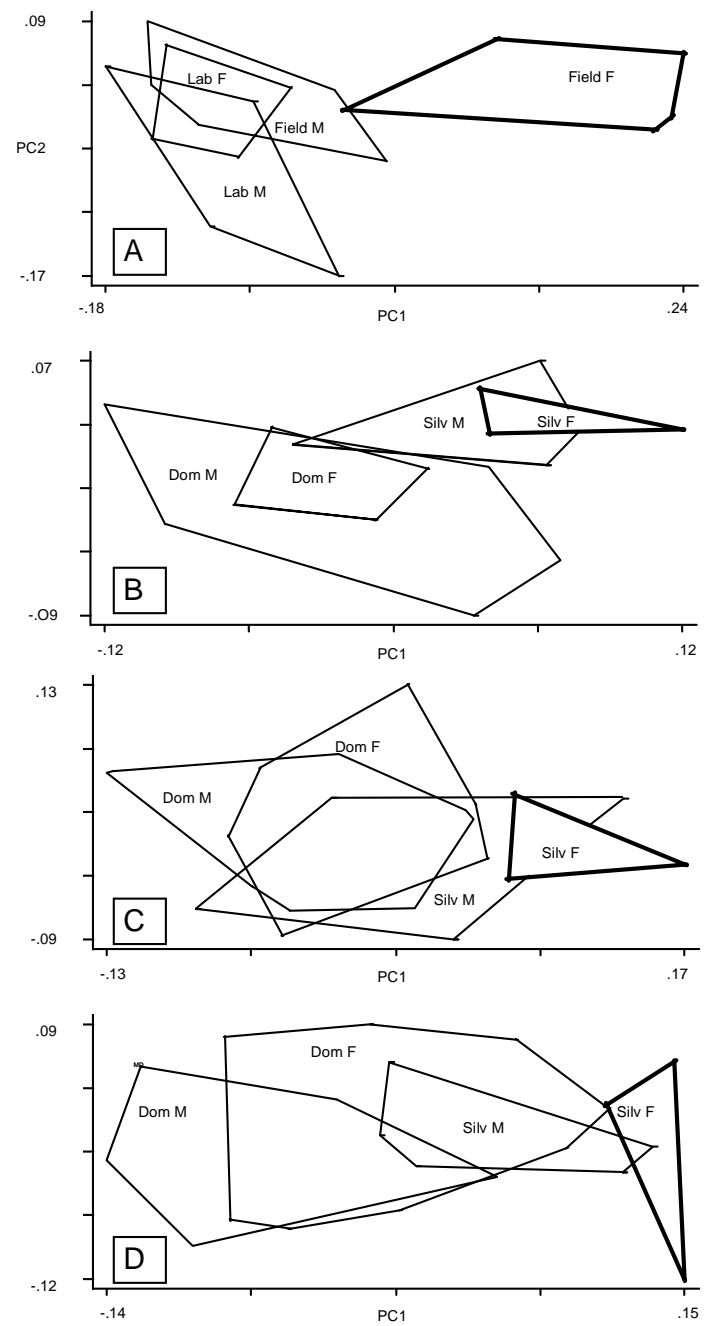

Fig. 2 : factor maps corresponding to Rhodnius domesticus (A, top) and three samples of Triatoma infestans (B, C, D). Female (F) and male (M) specimens of $R$. domesticus (A, top), either reared in laboratory (Lab F, Lab M) or recently collected in the field (Field F, Field M), are projected onto the first (PC1, 64\%) and second (PC2, 14\%) principal components. The three remaining factor maps (B, C, D) are female (F) and male (M) specimens of $T$. infestans, collected in house (Dom F, Dom M) or in silvatic ecotopes (Silv F, Silv M), projected onto PC1 and PC2; B, sample collected at Laguna Angostura in 1983; C, sample collected at Jamach'Uma in 1993 and D, sample collected at Jamach'Uma in 1996 (see Dujardin et al. 1997b). Convex hulls enclose specimens for each category. These four factor maps illustrate three main features in both $R$. domesticus and T. infestans: (i) no or poor sexual differentiation in laboratory or domestic habitat (compare Lab $\mathrm{M}$ and $\mathrm{Lab} \mathrm{F}$ in $R$. domesticus, Dom M and Dom F in T. infestans); (ii) significant sexual dimorphism in field, silvatic habitat (compare Field M and Field $\mathrm{F}$ in $R$. domesticus, Silv $\mathrm{M}$ and Silv $\mathrm{F}$ in T. infestans), and (iii) an important reduction of female head dimensions from field to either laboratory (compare Field $\mathrm{F}$ and Lab $\mathrm{F}$ in $R$. domesticus) or domestic habitats (compare Silv F and Dom F in T. infestans). Notice that in the 1996 sample (D, bottom), there was also a size difference between silvatic and domestic male T. infestans. 
also shown in the comparison by biotope, whereby males showed no significant metric differences but females showed a drastic size reduction going from field to laboratory populations (Table II, right). We reexamined the data presented by Harry (1992) on samples of Rhodnius collected from various localities in Venezuela. These data showed a lower level of sexual dimorphism in the six domestic samples of $R$. prolixus, and a pronounced dimorphism in the silvatic strain collected directly from palm tree habitats (determined as R. robustus by Harry 1994) (detailed results not shown).

Using the same Bonferroni tests, significant sexual dimorphism was detected only in the silvatic population of $T$. infestans, not in the domestic specimens, and the reduction in size of the head measurements between silvatic and domestic specimens was again more pronounced for females (Table III).

These changes in sexual size dimorphism were verified also after multivariate analyses: in all cases,

TABLE I

Metric properties of Rhodnius domesticus

\begin{tabular}{|c|c|c|c|c|c|c|c|c|}
\hline & \multicolumn{4}{|c|}{ Females } & \multicolumn{4}{|c|}{ Males } \\
\hline & \multicolumn{2}{|c|}{ Field } & \multicolumn{2}{|c|}{ Laboratory } & \multicolumn{2}{|c|}{ Field } & \multicolumn{2}{|c|}{ Laboratory } \\
\hline & Mean & SD & Mean & SD & Mean & SD & Mean & SD \\
\hline $\mathrm{OE}$ & 32 & 0.9 & 29 & 1.0 & 31 & 1.2 & 29 & 0.5 \\
\hline IE & 14 & 0.4 & 13 & 1.0 & 13 & 0.4 & 13 & 0.5 \\
\hline EO & 22 & 0.8 & 21 & 0.5 & 21 & 0.0 & 21 & 0.0 \\
\hline $\mathrm{AO}$ & 41 & 1.0 & 38 & 1.7 & 37 & 2.0 & 39 & 0.9 \\
\hline PO & 33 & 1.6 & 29 & 0.8 & 30 & 0.6 & 30 & 0.6 \\
\hline $\mathrm{HL}$ & 74 & 2.4 & 68 & 2.5 & 68 & 1.8 & 69 & 2.2 \\
\hline $\mathrm{DE}$ & 21 & 1.2 & 19 & 0.0 & 19 & 1.0 & 20 & 1.7 \\
\hline AT & 28 & 1.1 & 27 & 0.8 & 26 & 0.9 & 27 & 1.3 \\
\hline R1 & 18 & 0.5 & 16 & 0.5 & 17 & 0.5 & 17 & 1.3 \\
\hline R2 & 56 & 1.5 & 52 & 1.3 & 52 & 1.8 & 52 & 0.6 \\
\hline R3 & 17 & 0.5 & 16 & 1.0 & 16 & 0.5 & 15 & 1.0 \\
\hline AC & 20 & 1.0 & 18 & 0.5 & 19 & 0.8 & 18 & 0.5 \\
\hline
\end{tabular}

Mean and standard deviation (Stdev) in graduation units for 12 head measurements (OE to AC, see Fig. 1) for field and laboratory samples of female and male $R$. domesticus. All measurements were performed by the same investigator (TC) at 25x (OE, IE, EO, AO, PO, HL, DE, AT, R1, R2, R3) and 40x (PO, AC) magnification using a monocular micrometer. One micrometer graduation represented $20 \mu$ for the measurement $\mathrm{PO}$ and $\mathrm{AC}$ (50x magnification), and $40 \mu$ for the other head measurements (25x magnification).

TABLE II

Univariate analysis in Rhodnius domesticus

\begin{tabular}{|c|c|c|c|c|c|c|c|c|}
\hline & \multicolumn{4}{|c|}{ Between males and females } & \multicolumn{4}{|c|}{ Between field and laboratory } \\
\hline & \multicolumn{2}{|c|}{ Laboratory } & \multicolumn{2}{|c|}{ Field } & \multicolumn{2}{|c|}{ Females } & \multicolumn{2}{|c|}{ Males } \\
\hline & $\mathrm{P}$ & Bonf & $\mathrm{P}$ & Bonf & $\mathrm{P}$ & Bonf & $\mathrm{P}$ & Bonf \\
\hline $\mathrm{OE}$ & 0.3496 & NS & 0.0316 & NS & 0.0054 & $\mathrm{~S}$ & 0.0189 & NS \\
\hline IE & 0.1692 & NS & 0.0019 & S & 0.0189 & $\mathrm{~S}$ & 0.1155 & NS \\
\hline $\mathrm{EO}$ & 0.3173 & NS & 0.0093 & S & 0.0201 & $\mathrm{~S}$ & 1.0000 & NS \\
\hline $\mathrm{AO}$ & 0.8817 & NS & 0.0039 & S & 0.0149 & $\mathrm{~S}$ & 0.2352 & NS \\
\hline PO & 0.3428 & NS & 0.0054 & $\mathrm{~S}$ & 0.0079 & $\mathrm{~S}$ & 0.2225 & NS \\
\hline $\mathrm{HL}$ & 0.3807 & NS & 0.0032 & $\mathrm{~S}$ & 0.0120 & $\mathrm{~S}$ & 0.3850 & NS \\
\hline $\mathrm{DE}$ & 0.2155 & NS & 0.0179 & NS & 0.0280 & $\mathrm{~S}$ & 0.2188 & NS \\
\hline $\mathrm{AT}$ & 0.8770 & NS & 0.0038 & S & 0.0536 & $\mathrm{~S}$ & 0.1175 & NS \\
\hline $\mathrm{R} 1$ & 0.7568 & NS & 0.0014 & S & 0.0044 & $\mathrm{~S}$ & 1.0000 & NS \\
\hline $\mathrm{R} 2$ & 0.3428 & NS & 0.0049 & $S$ & 0.0077 & $\mathrm{~S}$ & 0.8236 & NS \\
\hline R3 & 0.1776 & NS & 0.0026 & S & 0.0363 & $\mathrm{~S}$ & 0.1461 & NS \\
\hline $\mathrm{AC}$ & 0.6171 & NS & 0.0612 & NS & 0.0280 & $\mathrm{~S}$ & 0.6446 & NS \\
\hline
\end{tabular}

Non-parametric comparisons (Kruskal \& Wallis 1952) at 12 head measurements (OE to AC, see Fig. 1) of $R$. domesticus, exploring sexual dimorphism in the laboratory and in the field collected samples (see columns "Laboratory" and "Field"), and biotope differences for each sex (see columns "Females" and "Males"). P, level of significance; Bonf, sequential Bonferroni test (after Sokal \& Rohlf 1995, p. 241). 


\section{TABLE III}

Univariate analysis in silvatic and domestic Triatoma infestans (data from Dujardin et al. 1997b)

\begin{tabular}{|c|c|c|c|c|c|c|c|c|}
\hline & \multicolumn{4}{|c|}{ Between males and females } & \multicolumn{4}{|c|}{ Between silvatic and domestic } \\
\hline & \multicolumn{2}{|c|}{$\begin{array}{c}\text { Domestic } \\
(40,33)\end{array}$} & \multicolumn{2}{|c|}{$\begin{array}{l}\text { Silvatic } \\
(20,10)\end{array}$} & \multicolumn{2}{|c|}{$\begin{array}{c}\text { Females } \\
(33,10)\end{array}$} & \multicolumn{2}{|c|}{$\begin{array}{c}\text { Males } \\
(40,20)\end{array}$} \\
\hline & $\mathrm{P}$ & Bonf & $\mathrm{P}$ & Bonf & $\mathrm{P}$ & Bonf & $\mathrm{P}$ & Bonf \\
\hline $\mathrm{OE}$ & 0.3299 & NS & 0.0907 & NS & 0.1951 & NS & 0.6801 & NS \\
\hline $\mathrm{PO}$ & 0.0380 & NS & 0.2231 & NS & 0.0001 & $\mathrm{~S}$ & 0.0123 & $\mathrm{~S}$ \\
\hline HL & 0.0258 & NS & 0.0056 & $\mathrm{~S}$ & 0.0011 & $\mathrm{~S}$ & 0.0201 & NS \\
\hline $\mathrm{AT}$ & 0.0281 & NS & 0.0543 & NS & 0.0039 & $\mathrm{~S}$ & 0.0008 & $\mathrm{~S}$ \\
\hline $\mathrm{R} 2$ & 0.1193 & NS & 0.5669 & NS & 0.0105 & $\mathrm{~S}$ & 0.1084 & NS \\
\hline
\end{tabular}

Non-parametric comparisons (Kruskal \& Wallis 1952) at 5 head measurements (see Dujardin et al. 1997b) of $T$. infestans, exploring sexual dimorphism in domestic and silvatic samples (see columns "Domestic" and "Silvatic"), and ecotope differences for each sex (see columns "Females" and "Males"). P, level of significance; Bonf, sequential Bonferroni test (after Sokal \& Rohlf 1995, p. 241).

sexual dimorphism was reduced in domestic or laboratory populations compared to silvatic populations, and the changes seemed mainly due to a reduction in size of the females (Fig. 2).

\section{DISCUSSION}

The existence of sexual dimorphism in Triatominae is well known, with females, on average, being larger than males (Lent \& Wygodzinsky 1979). No previous study has examined the fate of this dimorphism in different habitats, although a general reduction in body size has been noted for bugs reared over successive generations in the laboratory (Szumlewicz 1976, Zeledón 1981). This has been suggested to be due to a longer generation time in natural habitats, as a result of several incomplete bloodmeals delaying the successive moults (Zeledón et al. 1970, Zeledón 1981), but more simply could be due to improved survivorship of smaller individuals in the laboratory (Schofield 1996). Other observations also show that domestic specimens, on average, tend to be smaller than their silvatic conspecifics (Harry 1994, Dujardin et al. 1997a,b), which could again be due to improved survivorship in domestic habitats. The present study provides a quantitative analysis of these changes, and reveals that in the material examined the reduction in average size could be mainly due to size reductions in female bugs, leading to a corresponding reduction in sexual dimorphism.

We believe that, more than a direct relation with silvatic and domestic habitats, our observation could reveal the effect of population density on bugs size. Indeed, in a population near its carrying capacity - which is generally the case in domestic or laboratory populations - each individual would get less blood because of competition and would then be smaller, especially among the females with greater food requirements. Due to higher survivorship in domestic or laboratory colonies, smaller individuals would survive and the average size decrease, especially in females.

According to that hypothesis, and as long as the population density generally increases from silvatic to domestic habitats, we can expect modifications in sexual dimorphism in the transition of bugs from silvatic to domestic habitats, and suggest that this feature could be used in the study of this transition in other species.

\section{REFERENCES}

Bookstein FL 1989. "Size and shape": a comment on semantics. Syst Zool 38: 173-180.

Dos Reis SF, Pessoa LM, Strauss RE 1990. Application of size-free canonical discriminant analysis to studies of geographic differentiation. Braz J Gen 13: 509520.

Dujardin JP, Casini C 1996. Morphometry of Triatoma infestans, p. 53-54. In CJ Schofield, JP Dujardin, J Jurberg (eds), Proceedings of the International Workshop on Population Genetics and Control of Triatominae, Santo Domingo de los Colorados, Ecuador, INDRE, Mexico City, 116 pp.

Dujardin JP, Bermudez H, Schofield CJ 1997a. The use of morphometrics in entomological surveillance of silvatic foci of Triatoma infestans in Bolivia. Acta Trop 66: 145-153.

Dujardin JP, Bermudez H, Casini C, Schofield CJ, Tibayrenc M 1997b. Metric differences between silvatic and domestic Triatoma infestans (Hemiptera: Reduviidae) in Bolivia. J Med Entomol 34: 544-551.

Galvão AB, Mello LR, Ferreira Neto JA, Leal H 1962. Sobre a distribução geográfica e infecção natural do Rhodnius domesticus Neiva \& Pinto, 1923. Rev Bras Malariol Doenças Trop 13: 57-60. 
Harry M 1992. Variabilité Génétique de Populations Vénézuéliennes de Rhodnius spp. Vectrices de Trypanosoma cruzi, Parasite Responsable de la Maladie de Chagas, Thesis, Université de Paris VI, 200 pp.

Harry M 1994. Morphometric variability in the Chagas disease vector Rhodnius prolixus. Jap J Gen 69: 233250.

Kruskal WH, Wallis, WA 1952. Use of ranks in onecriterion variance analysis. J Am Stat Assoc 47: 583621.

Leal H, Ferreira Neto AF, Martins CM 1961. Dados ecológicos sobre os triatomineos silvestres na Ilha de Santa Catarina (Brasil). Rev Inst Med Trop São Paulo 3: 213-220.

Lent H, Wygodzinsky P 1979. Revision of the Triatominae (Hemiptera, Reduviidae), and their significance as vectors of Chagas disease. Bull Am Mus Nat Hist 163: 123-520.

Schlemper Jr BR, Steindel M, Gargioni R, Farias CJM, Oliveira R, Trianon JAX 1985. Reservatorios e vetores silvestres do Trypanosoma cruzi e suas relações com o domicílio humano na Ilha de Santa Catarina. Arq Catar de Med 14: 91-96.

Schofield CJ 1996. Overview - Biosystematics of the Reduviidae, p. 45-50 . In CJ Schofield, JP Dujardin,
J Jurberg (eds), Proceedings of the International Workshop on Population Genetics and Control of Triatominae, Santo Domingo de los Colorados, Ecuador, INDRE, Mexico City, 116 pp.

Sokal RR, Rohlf JF 1995. Biometry: the Principles and Practice of Statistics in Biological Research, 3rd ed, WH Freeman \& Co., New York, 887 pp.

Steindel M, Carvalho Pinto JC, Toma HK, Ribeiro Rodrigues R, Romanha AJ 1991. Trypanosoma rangeli (Tejera, 1920) isolated from a silvatic rodent (Echimys dasytrix) in Santa Catarina Island, Santa Catarina State: first report of this trypanosome in southern Brazil. Mem Inst Oswaldo Cruz 86: 73-79.

Szumlewicz AP 1976. Laboratory colonies of Triatominae, biology and population dynamics, $\mathrm{p}$. 63-82. In American Trypanosomiasis Research, PAHO Scientific Publication 318, Washington DC.

Zeledón R 1981. El Triatoma dimidiata y su Relación con la Enfermedad de Chagas, Editorial EUNED, Costa Rica, 146 pp.

Zeledón R, Guardia VM, Zuñiga A, Swartzwelder JC 1970. Biology and ethology of Triatoma dimidiata (Latreille, 1811) I. Life cycle, amount of blood ingested, resistance to starvation, and size of adults. $J$ Med Entomol 7: 313-319. 
Sexual Dimorphism Variation in Triatominae - JP Dujardin et al. 